\title{
BMJ Open Health-related quality of life among frequent attenders in Swedish primary care: a cross-sectional observational study
}

Ylva Strömbom, ${ }^{\oplus 1,2}$ Peter Magnusson, ${ }^{\oplus 1,3}$ Jan Karlsson, ${ }^{4}$ Mats Fredrikson ${ }^{2,5}$

To cite: Strömbom Y, Magnusson P, Karlsson J, et al. Health-related quality of life among frequent attenders in Swedish primary care: a cross-sectional observational study. BMJ Open 2019;9:e026855. doi:10.1136/ bmjopen-2018-026855

- Prepublication history for this paper is available online. To view these files please visit the journal online (http://dx.doi org/10.1136/bmjopen-2018026855).

Received 27 September 2018 Revised 22 December 2018 Accepted 13 June 2019

Check for updates

(c) Author(s) (or their employer(s)) 2019. Re-use permitted under CC BY-NC. No commercial re-use. See rights and permissions. Published by BMJ.

${ }^{1}$ Centre for Research and Development, Region Gavleborg, Gavle, Sweden

${ }^{2}$ Department of Psychology, Uppsala Universitet, Uppsala, Sweden

${ }^{3}$ Cardiology Research Unit, Department of Medicine, Karolinska Institutet, Stockholm, Sweden

${ }^{4}$ University Health Care Research Center, Örebro University, Örebro, Sweden

${ }^{5}$ Department of Clinical

Neuroscience, Karolinska Institutet, Stockholm, Sweden

Correspondence to

Ylva Strömbom;

ylva.strombom@

regiongavleborg.se

\section{ABSTRACT}

Objectives The aim was to examine health-related quality of life (HRQoL), patient characteristics and reasons for visits to general practitioners (GPs) by frequent attenders (FAs) and a comparison group (CG) in primary care. Methods Patients aged 18-64 years were eligible for the study. Medical records were scrutinised concerning reasons for visits. Questionnaires including short-form health survey (SF-36) were mailed to 331 FAs ( $\geq 5$ visits at GPs during 2000) and 371 patients in a CG randomly selected from two healthcare centres and returned by $49 \%$ and $57 \%$, respectively. FAs' SF-36 health profiles were compared both to $\mathrm{CG}$ and general Swedish population norms.

Results FAs report lower HRQoL than CG and below the general Swedish population norms in all eight SF-36 domains including both mental and physical component summary scores (MCS and PCS). Effect sizes (ESs) for differences between FAs and norms ranged from 0.79 to 1.08 for specific domains and was 0.94 for PCS and 0.71 for MCS. ESs of FAs versus CG ranged between 0.60 and 0.95 for the domains and was 0.76 for PCS and 0.49 for MCS. There were no significant differences between the FAs and CG with regard to sex, being married or cohabiting, number of children in household or educational level. FAs were more often unemployed, obese, slightly older and used complementary medicine more frequently. Except for injuries, all health complaints as classified in 10 categories were more common among FAs than CG, particularly musculoskeletal pain and psychosocial distress related to compromised HRQoL.

Conclusion The HRQOL is compromised in FAs, both when compared with patients who do not often seek care and to general Swedish population norms. Commonly reported reasons for visiting GPs among FAs were musculoskeletal pain and psychosocial distress. Thus, perceived ill health, particularly pain and distress, seems important for high utilisation of healthcare resources.

\section{INTRODUCTION}

Frequent attenders (FAs) are those patients who most often seek medical consultations. FAs in primary care utilise a vast amount of resources across several countries and their healthcare systems. ${ }^{1}$ In addition to frequent

\section{Strengths and limitations of this study}

- This study revealed patients' own stated reason for consultation based on reviews of medical records without any selection bias.

- Patients aged 18-64 years were potentially eligible for employment. All patients were covered by Swedish national healthcare insurance which allows for similar access to care.

- Both the frequent attenders and comparison group cohorts are representative samples of the Swedish primary care population; however, no long-term follow-up data were collected.

- The total healthcare usage provided by secondary care facilities and other community-based support was not studied.

- Like most other studies, data on healthcare consumption were provided by general practitioners, and our study shares the limitations of generalisability due to its cultural context in a specific healthcare system.

visits to their general practitioner (GP), they also consume a large proportion of healthcare resources and thereby reduce the resources available to other patients.

Typically, $3 \%-5 \%$ of the general population uses $15 \%-25 \%$ of the available visits to GPs. ${ }^{2-4}$ In England, ${ }^{5} 3 \%$ of patients accounted for $15 \%$ of all visits to GPs and similar experiences were reported in Sweden ${ }^{4}$ and Canada. ${ }^{6}$ There is a need to investigate if the consulting patterns of FA are appropriate and, if not, how their help-seeking behaviour may be altered. By increased understanding of the consulting behaviours of FAs, strategies for interventions may be developed. ${ }^{7}$

In general, two approaches have been used to characterise the FA group. One strategy is to define a cut-off based on the distribution of all GP consultations. It has been suggested that patients above the 75th or 90th percentile of the distribution should be classified as FAs. ${ }^{18-14}$ Another approach is to define a 
maximum number of consultations for normal healthcare consumption and consider patients who exceed this cut-off as FAs. ${ }^{1} 681014-19$

In order to explain why some patients seek help from GPs more often than others, several factors should be considered. Women are more common among FAs in primary care; however, women seek healthcare more often in general ${ }^{1}$ and comprise the majority among both FAs and non-FAs. ${ }^{1615-182021}$

Moreover, the older and children visit their GPs more often than people of working age (18-64 years). ${ }^{21}$ In Sweden, the working age population is covered by a national health insurance system, which deserves special attention from a societal perspective. Low-socioeconomic status (ie, low education, unemployment, low income, marital breakdown and being single) is associated with a higher risk of being an FA. ${ }^{1681113151820}$ This may reflect underlying social and medical factors such as loneliness, ${ }^{22} 23$ psychosocial reactions to physical symptoms, changing symptoms over time, ${ }^{24}$ having more severe symptoms or symptoms usually ignored by others, ${ }^{25}$ a high prevalence of chronic illness or other physical disease, ${ }^{1213}$ psychiatric disorders ${ }^{14}$ and a less healthful lifestyle. ${ }^{26}$ It seems that these sorts of complaints are similar between FAs and other patients. ${ }^{1}$

In a British study, FAs reported worse health-related quality of life (HRQoL) compared with controls in all dimensions (mobility, self-care, usual activities, pain/ discomfort and anxiety/depression) as measured by the EQ-5D. ${ }^{27}$ Pain as on the SF-12 was strongly associated with frequent attendance in an Australian study. ${ }^{28}$

Despite all that is known regarding FAs and their characteristics, there are still gaps in the understanding of the mechanisms that underlay their high consumption of healthcare. It has been suggested that processes associated with mental rather than somatic factors are pivotal in influencing help-seeking behaviours in FAs. Because FAs most often visit their GPs, this cross-sectional study aims to evaluate FAs' patient characteristics and reasons for visits to GPs in relation to the HRQoL as measured by the 36-item short-form health survey (SF-36), and compared with both population norms and a comparison group (CG).

\section{METHODS \\ Setting}

The city Sandviken in Region Gävleborg, Sweden, had 23028 inhabitants when data were collected. ${ }^{29}$ A total of 11 physicians (seven specialists in general medicine and four residents) served a catchment area of approximately 14000 at two healthcare centres in Björksätra and Vallhov.

\section{Frequent attenders and comparison group}

We selected all FAs with $\geq 5$ visits to GP during the year $2000(\mathrm{n}=395)$. The $\mathrm{CG}$ was selected $(\mathrm{n}=395)$ by a random sampling out of remaining patients. Participants in both groups were between 18 and 65 years of age.

\section{Data sources}

Medical records, Profdoc Journal III were scrutinised and validated by the first author after consultation of an expert in the field. The main reason(s) for physician consultation were classified according to ten categories covering major health problems: musculoskeletal pain, infections, psychosocial distress, digestive problems, skin complaints, injuries, genitourinary complaints, headache and tinnitus, circulatory complaints and respiratory complaints. This categorisation was based on the Public Health Report $1997,{ }^{30}$ previous research findings ${ }^{31}$ and was derived from patients' stated reason(s) for visits rather than diagnoses.

\section{The questionnaires}

We mailed an envelope with information about the study, SF-36 version 1, and questions about the subjects' civil status (married/cohabitating/single, children in the household), employment, education, height, weight, use of naturopathic drugs and alternative medical consultations. Two reminders were sent when appropriate.

Exclusion criteria were severe mental or somatic disorders, the need for an interpreter, ongoing alcohol- and/ or drug misuse, and severe disabilities such as mental retardation. A total of 88 patients were excluded, of whom 64 were FAs.

The questionnaires and a return envelope were sent to 702 patients: 331 FAs and 371 patients in the CG. The response rate was $49 \%$ among FAs and $57 \%$ among CG, respectively. The participant flow-chart is depicted in figure 1.

\section{SF-36 domains and general Swedish population norms}

SF-36 is a widely recognised generic HRQoL instrument developed in the Medical Outcome Study and used since the 1990s. ${ }^{32}$ The 36 items in the instrument measure eight domains that cover physical and mental health aspects: physical functioning (PF), role-physical (RP), bodily pain (BP), general health $(\mathrm{GH})$, vitality (VT), social functioning (SF), role-emotional (RE) and mental health $(\mathrm{MH})$. The score of each domain ranges between 0 and 100, where a higher value indicates better HRQoL. Furthermore, the physical component summary (PCS) score and the mental component summary (MCS) score are derived from the eight domains. PCS and MCS scores are norm-based with a mean of 50 in the general population. A value above 50 is interpreted as a better HRQoL than the general population.

The SF-36 data in the FA group and CG were compared with an age-matched and sex-matched sample $(n=1524)$ randomly selected from the Swedish SF-36 normative database from 1991 to $1992(\mathrm{n}=8930) .^{33}$

\section{Statistics}

Categorical data were described as numbers and percentages and compared by $\mathrm{X}^{2}$ tests, while ordinal/continuous data were reported as means (including SD and 95\% CI), median, percentiles and were compared using t-tests. 


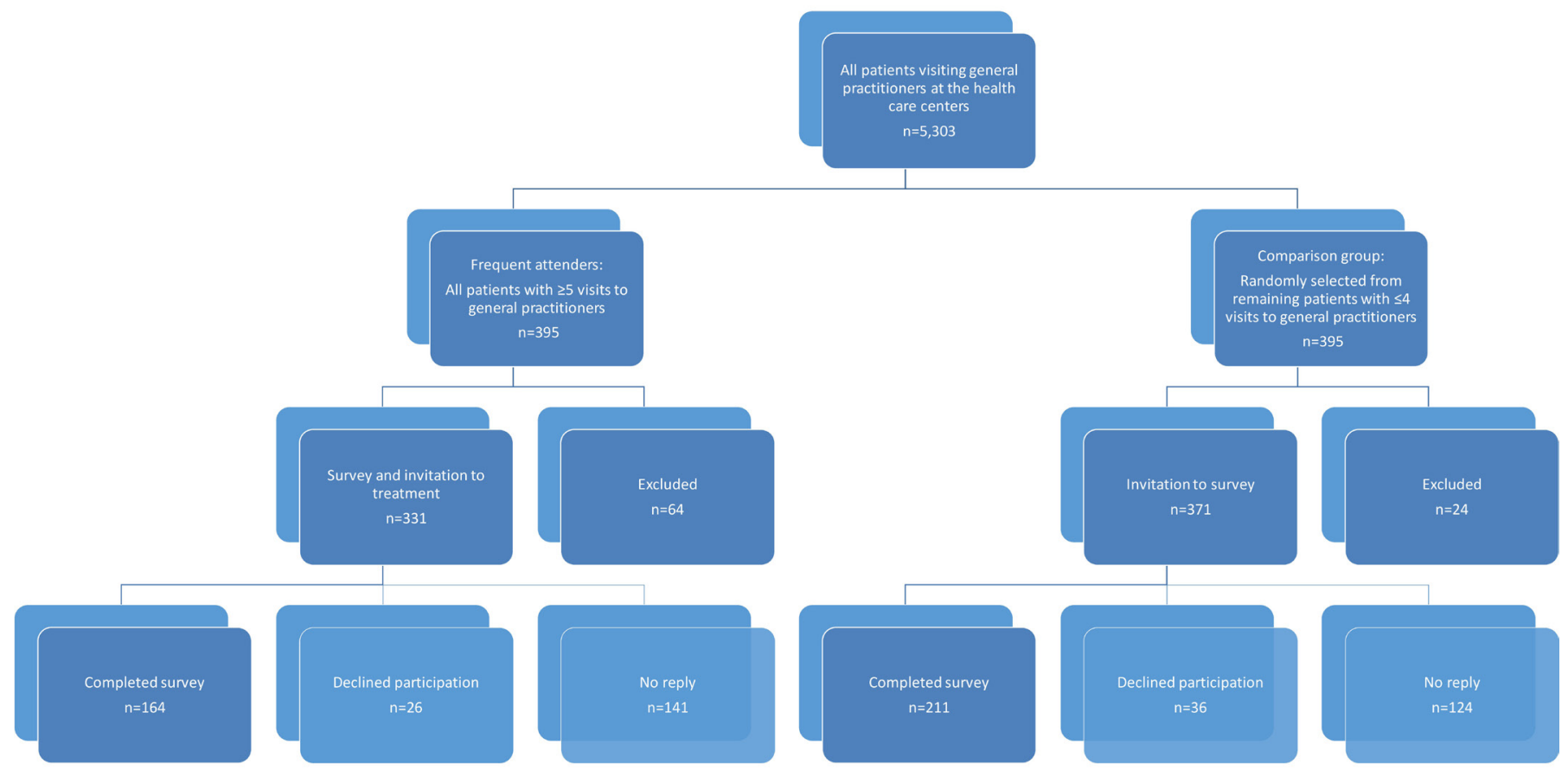

Figure 1 Participant flowchart. All patients who fulfilled the inclusion criteria regarding frequent attendance were included in the study. The comparison group was randomly selected from the remaining patients. Exclusion criteria were severe mental or somatic disorder (eg, schizophrenia, anorexia and cancer), need for interpreter (due to other native language or deafness), ongoing alcohol- and/or drug misuse and severe disabilities, such as mental retardation.

The non-parametric Mann-Whitney U test was used for between-group comparisons of SF-36 domains. Cohen's $\mathrm{d}$ was used to calculate the effect size (ES) of betweengroup differences. ES was interpreted according to standard criteria: trivial $(<0.20)$, small $(0.20-0.49)$, moderate $(0.50-0.79)$ and large $(\geq 0.80) .{ }^{34}$ SPSS V.22 was used for statistical analyses. A two-sided $\mathrm{p}$ value of less than 0.05 was considered significant.

\section{Patient and public involvement statement}

Patients and public were neither involved in developing the hypothesis, the specific aims or the research questions, nor were they involved in developing plans for design or implementation of the study.

\section{RESULTS}

\section{Patient characteristics}

The characteristics of patients and their major health complaints are summarised in table 1. In total, 164 FAs and 211 patients in the CG were analysed. There was no significant difference with regard to sex, as $69.5 \%$ were females among FAs and $62.1 \%$ in the CG. The mean age was significantly higher in FAs, 46.8 years versus 43.8 years in the CG $(p=0.018)$. There were similar proportions of married/cohabitating individuals, child(ren) at home and educational levels, but a larger proportion of the CG was gainfully employed compared with the FA group $(79.4 \%$ vs $67.3 \%$, respectively, $\mathrm{p}=0.009)$. There was no difference between groups in the use of naturopathic drugs, whereas use of complementary medicine was more common in FAs $(\mathrm{p}=0.003)$. Notably, a significantly higher proportion of FAs $(28.2 \%)$ had a body mass index $(\mathrm{BMI}) \geq 30$ compared with the CG $(12.1 \%) \quad(\mathrm{p}<0.001)$.

In all 10 health problem categories except injuries, reports of complaints were more common among FAs than the CG (table 1).

Musculoskeletal pain was the most common complaint among FAs followed by infections, psychosocial distress and digestive problems. In contrast, infections were more common among the CG than musculoskeletal pain followed by psychosocial distress and digestive problems.

\section{SF-36 in FAs, the CG and a Swedish norm population}

Comparisons of SF-36 scores showed significant differences between FAs and the Swedish norm population as well as between FAs and the CG in all eight domains and the two component scores $(\mathrm{p}<0.0001)$ (figure 2 and table 2). The ES of the differences between FA and general Swedish population norms were large for $7 / 8$ domains (range 0.79-1.08), large for PCS (0.94) and moderate for MCS (0.71). ESs of comparisons between FAs and CG were moderate to large for the domains (range 0.60-0.95), moderate for PCS (0.76) and small for MCS (0.49).

\section{Subgroup analyses among FAs}

The health complaint categories described in the Methods section were used to categorise patients based on who did or did not report a certain complaint. SF-36 health profiles were then evaluated in those with or without that specific complaint 
Table 1 Characteristics of frequent attenders and a comparison group

\begin{tabular}{|c|c|c|c|}
\hline & Frequent attenders & Comparison group & \\
\hline Variable & $\mathrm{n}=164$ & $\mathrm{n}=\mathbf{2 1 1}$ & $P$ value \\
\hline Age, mean (SD) & 46.8 (SD 11.3) & 43.8 (SD 12.7) & 0.018 \\
\hline Female sex & $114(69.5 \%)$ & $131(62.1 \%)$ & 0.155 \\
\hline Married/cohabitate & $119(73.9 \%)$ & $163(79.9 \%)$ & 0.209 \\
\hline Child(ren) at home & $66(40.5 \%)$ & $90(42.7 \%)$ & 0.751 \\
\hline University & $19(13.0 \%)$ & $34(17.1 \%)$ & 0.365 \\
\hline Employed & $109(67.3 \%)$ & $166(79.4 \%)$ & 0.009 \\
\hline Body mass index $\left(\mathrm{kg} / \mathrm{m}^{2}\right) \geq 30$ & $44(28.2 \%)$ & $25(12.1 \%)$ & $<0.001$ \\
\hline Naturopathic drug use & $45(27.8 \%)$ & $56(27.1 \%)$ & 0.907 \\
\hline Complementary medicine use & $57(35.4 \%)$ & $43(21.2 \%)$ & 0.003 \\
\hline \multicolumn{4}{|l|}{ Health complaint categories* } \\
\hline Musculoskeletal pain & $126(76.8 \%)$ & $82(38.8 \%)$ & $<0.001$ \\
\hline Infections & $115(70.1 \%)$ & $90(42.7 \%)$ & $<0.001$ \\
\hline Psychosocial distress & $77(47.0 \%)$ & $45(21.3 \%)$ & $<0.001$ \\
\hline Digestive problems & $58(35.4 \%)$ & $38(18.0 \%)$ & $<0.001$ \\
\hline Skin complaints & $48(29.3 \%)$ & $32(15.2 \%)$ & 0.001 \\
\hline Injuries & $35(21.3 \%)$ & $33(15.6 \%)$ & 0.177 \\
\hline Headache and tinnitus complaints & $42(25.6 \%)$ & $17(8.1 \%)$ & $<0.001$ \\
\hline Genitourinary complaints & $40(24.4 \%)$ & $26(12.3 \%)$ & 0.003 \\
\hline Circulatory complaints & $41(25.0 \%)$ & $30(14.2 \%)$ & 0.011 \\
\hline Respiratory complaints & $44(26.8 \%)$ & $19(9.0 \%)$ & $<0.001$ \\
\hline
\end{tabular}

${ }^{*}$ Based on review of medical records.

(table 3 ). In addition, we analysed obese (BMI $\geq 30$ ) versus non-obese patients and male patients versus female patients (table 4). The presence of musculoskeletal pain was related to worse scores on PF, BP and PCS (ES 0.34, 0.52 and 0.61, respectively). Reports of psychosocial distress were related to worse scores on VT, SF, RE, MH and MCS (ES 0.44, 0.40, 0.34, 0.33 and 0.43 , respectively). Infections were associated with better SF-36 scores on all domains except for PF and SF (ESs ranged from 0.37 to 0.62 for the domains and ES for MCS was 0.56). Circulatory complaints affected PF (ES 0.44) and PCS (ES 0.39) and a BMI over 30 was related to worse scores for PF (ES 0.72) and GH (ES 0.32).
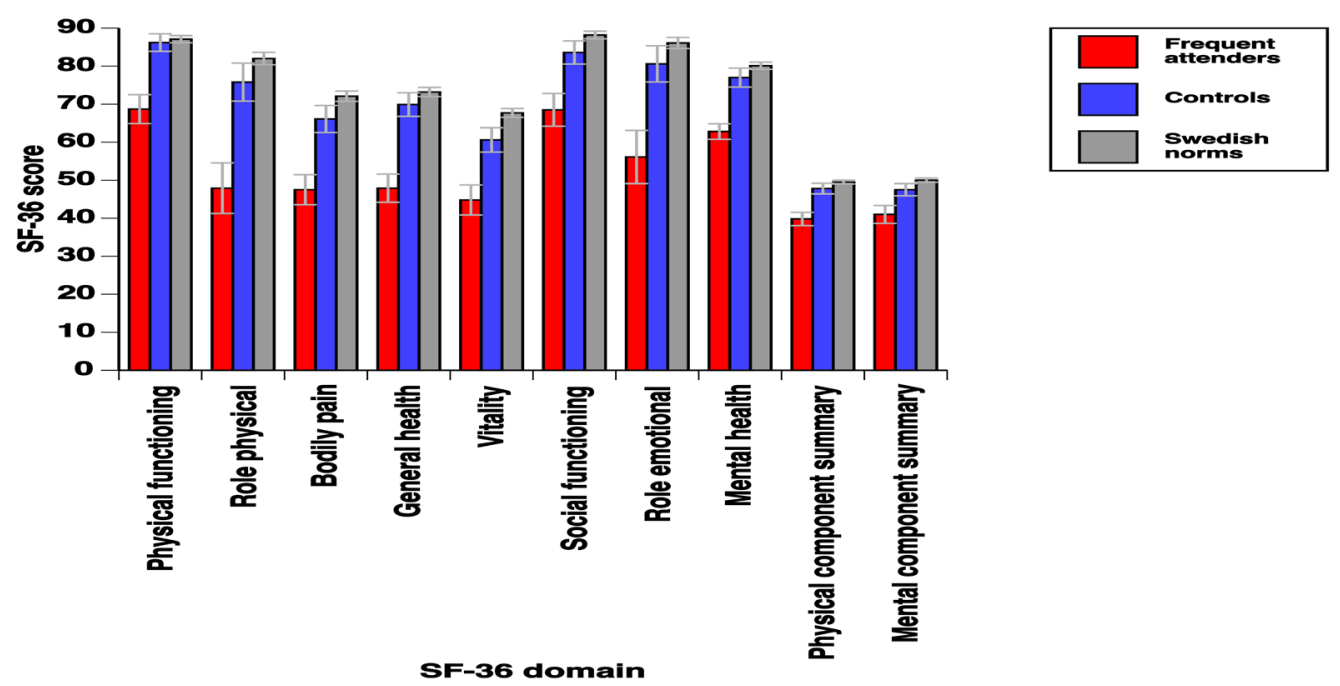

Figure 2 Short-form health survey (SF-36) score in frequent attenders in primary care compared with a comparison group and Swedish population norms. 
Table 2 Short-form health survey (SF-36) scores in frequent attenders in primary care as compared with general Swedish population norms and a comparison group

\begin{tabular}{|c|c|c|c|c|c|c|c|c|}
\hline \multirow[b]{2}{*}{ SF-36 domains } & \multicolumn{2}{|c|}{$\begin{array}{l}\text { Frequent attenders } \\
\text { (FA, } n=164)\end{array}$} & \multicolumn{2}{|c|}{$\begin{array}{l}\text { Swedish population } \\
\text { norms ( } n=1524)\end{array}$} & \multirow{2}{*}{$\begin{array}{l}\text { FA } \\
\text { vs norms* } \\
\text { Effect size }\end{array}$} & \multicolumn{2}{|c|}{$\begin{array}{l}\text { Comparison group } \\
\text { (CG, } n=211)\end{array}$} & \multirow{2}{*}{$\frac{\text { FA vs } \text { CG }^{*}}{\text { Effect size }}$} \\
\hline & Mean (SD) & $95 \% \mathrm{Cl}$ & Mean (SD) & $95 \% \mathrm{Cl}$ & & Mean (SD) & $95 \% \mathrm{Cl}$ & \\
\hline $\begin{array}{l}\text { Physical } \\
\text { functioning }\end{array}$ & $68.7(24.6)$ & 64.9 to 72.5 & $87.1(18.5)$ & 86.2 to 88.1 & 0.84 & $86.2(17.0)$ & 83.9 to 88.5 & 0.83 \\
\hline Role physical & $47.9(42.6)$ & 41.2 to 54.5 & $82.0(32.4)$ & 80.4 to 83.7 & 0.90 & $75.8(36.8)$ & 70.8 to 80.8 & 0.70 \\
\hline Bodily pain & $47.5(25.4)$ & 43.6 to 51.5 & $72.1(26.8)$ & 70.8 to 73.5 & 0.94 & $66.1(26.0)$ & 62.6 to 69.7 & 0.72 \\
\hline General health & $47.9(23.8)$ & 44.2 to 51.6 & $73.2(23.2)$ & 72.0 to 74.4 & 1.08 & $69.9(22.4)$ & 66.8 to 73.0 & 0.95 \\
\hline Vitality & $44.8(25.4)$ & 40.8 to 48.7 & $67.7(23.1)$ & 66.6 to 68.9 & 0.94 & $60.6(23.8)$ & 57.4 to 63.8 & 0.64 \\
\hline $\begin{array}{l}\text { Social } \\
\text { functioning }\end{array}$ & $68.5(27.8)$ & 64.2 to 72.8 & $88.2(20.2)$ & 87.2 to 89.2 & 0.81 & $83.6(22.4)$ & 80.5 to 86.6 & 0.60 \\
\hline Role emotional & $56.1(44.8)$ & 49.1 to 63.2 & $86.1(28.1)$ & 84.7 to 87.6 & 0.80 & $80.6(34.7)$ & 75.9 to 85.4 & 0.61 \\
\hline Mental health & $62.8(24.1)$ & 59.1 to 66.6 & $80.0(19.1)$ & 79.0 to 80.9 & 0.79 & $77.0(18.3)$ & 74.5 to 79.4 & 0.66 \\
\hline $\begin{array}{l}\text { Physical } \\
\text { component } \\
\text { summary }\end{array}$ & $39.8(11.0)$ & 38.1 to 41.6 & 49.5 (9.6) & 49.0 to 50.0 & 0.94 & $47.8(10.1)$ & 46.4 to 49.2 & 0.76 \\
\hline $\begin{array}{l}\text { Mental } \\
\text { component } \\
\text { summary }\end{array}$ & $41.0(14.7)$ & 38.7 to 43.4 & $50.0(10.2)$ & 49.4 to 50.5 & 0.71 & $47.5(11.4)$ & 45.9 to 49.1 & 0.49 \\
\hline
\end{tabular}

*All comparisons FA versus Norms and FA versus CG are significant $(p<0.0001)$. Mann-Whitney $U$ test was used for between-group comparisons of SF-36 domains.

\section{DISCUSSION}

FAs reported compromised QoL accompanied by increased health complaints in most health areas. In addition, FAs were characterised by a higher degree of unemployment compared with CG. Unemployment or sick leave was over-represented among FAs in a previous Swedish study. ${ }^{35}$ However, a direct comparison between these two studies is limited by different age distributions, since our study excluded children and older individuals. Unemployment and civil status have been linked to frequent attendance, ${ }^{1536}$ but after adjustment of co-factors (age, sex, civil status, chronic disease, sickness/disability pension, life events, social integration, emotional support and sense of coherence) differences disappear. ${ }^{35}$ Here, cohabiting or being married did neither influence frequent attendance, nor did the number of children at home nor the patient's educational level. Although the FAs were statistically significantly older than the $\mathrm{CG}$, previous interpretations of age differences in this context ${ }^{35} 37$ consider that an age difference of 3 years is not clinically significant. Furthermore, there were not significantly more women than men among FAs, which also is in line with previous findings. ${ }^{1438}$

FAs in our study sought complementary medicine more often than CG. In a systematic review, female sex, middle age and higher education were identified as predictors for use of complementary medicine. ${ }^{39}$ Patients who try complementary medicine are known to use primary and secondary care frequently and take an active approach to their health problems. ${ }^{40}$ We believe that FAs are eager to solve their health problems as evidenced by their visits to primary care and perhaps a lack of results from the conventional healthcare system triggers their interest in looking at alternative medical treatments. Obesity $(\mathrm{BMI} \geq 30)$ is a condition associated with increased risk for a wide range of health problems and serious illnesses. Our study showed that FAs were more obese than CGs and the prevalence of obesity among FAs (28.2\%) was three times higher than the adult Swedish population in the year 2000. ${ }^{41}$ However, previous studies have been inconsistent, as a British study found that obesity was more common among $\mathrm{FAs},{ }^{27}$ while a US study did not confirm this. ${ }^{42}$

Kersnik $e t a l^{37}$ pointed out that most FAs were content with their GP and argued that anxiety and depression are valid reasons for FAs to visit their GPs. Another explanation may be that FAs simply are content with their previous visits and perceive their GP as a part of their social network. In the present study, FAs' reasons for visiting GPs reflected the most common health problems in the Swedish population. Previous research on reasons for visits have been based on diagnostic data, ${ }^{28}{ }^{35}$ whereas in the present study, data were derived from medical records without using the final diagnosis made by the GP. Our approach limits the possibility that GPs' assessments might influence the reported reasons for seeking healthcare. Ten health complaint categories used here seem to cover most of the symptoms presented by patients in primary care, and also to have equivalents in the International Classification of Primary Care system of classification for primary care. ${ }^{314344}$ Our data suggest that perceived ill health is the main driver of health-seeking behaviour. 
Table 3 Subgroup analyses of differences in short-form health survey (SF-36) scores among frequent attenders based on reported symptomatology. Differences are evaluated in those with versus without a specific health complaint and expressed as effect size for significant $(p<0.05)$ results.

\begin{tabular}{|c|c|c|c|c|c|c|c|c|}
\hline \multirow[b]{2}{*}{ SF-36 domains } & \multicolumn{2}{|c|}{$\begin{array}{l}\text { Musculoskeletal } \\
\text { pain }\end{array}$} & \multicolumn{2}{|c|}{ Infections } & \multicolumn{2}{|c|}{$\begin{array}{l}\text { Psychosocial } \\
\text { distress }\end{array}$} & \multicolumn{2}{|c|}{ Digestive problems } \\
\hline & $P$ value & ES & $P$ value & ES & $P$ value & ES & $P$ value & ES \\
\hline Physical functioning & 0.025 & 0.34 & \multicolumn{2}{|l|}{0.063} & \multicolumn{2}{|l|}{0.541} & \multicolumn{2}{|l|}{0.260} \\
\hline Role physical & \multicolumn{2}{|l|}{0.083} & \multicolumn{2}{|l|}{0.011} & \multicolumn{2}{|l|}{0.875} & \multicolumn{2}{|l|}{0.272} \\
\hline Bodily pain & 0.017 & 0.52 & 0.021 & $0.46^{*}$ & 0.257 & & \multicolumn{2}{|l|}{0.115} \\
\hline General health & \multicolumn{2}{|l|}{0.550} & 0.047 & $0.37^{*}$ & 0.170 & & \multicolumn{2}{|l|}{0.273} \\
\hline Vitality & \multicolumn{2}{|l|}{0.500} & \multicolumn{2}{|l|}{0.004} & 0.003 & 0.44 & 0.919 & \\
\hline Social functioning & \multicolumn{2}{|l|}{0.568} & \multicolumn{2}{|l|}{0.119} & 0.011 & 0.40 & \multicolumn{2}{|l|}{0.293} \\
\hline Role emotional & \multicolumn{2}{|l|}{0.227} & \multicolumn{2}{|l|}{0.001} & 0.034 & 0.34 & 0.141 & \\
\hline Mental health & 0.409 & & 0.002 & $0.55^{*}$ & 0.044 & 0.33 & 0.188 & \\
\hline Physical component summary & 0.002 & 0.61 & 0.187 & & 0.816 & & 0.081 & \\
\hline Mental component summary & 0.237 & & 0.002 & $0.56^{*}$ & 0.015 & 0.43 & 0.287 & \\
\hline & Skin cor & nplaints & Injuries & & $\begin{array}{l}\text { Headac } \\
\text { tinnitus }\end{array}$ & & $\begin{array}{l}\text { Genitou } \\
\text { complai }\end{array}$ & \\
\hline SF-36 domains & $P$ value & ES & $P$ value & ES & $P$ value & ES & $P$ value & ES \\
\hline Physical functioning & 0.627 & & 0.463 & & 0.454 & & 0.643 & \\
\hline Role physical & 0.858 & & 0.511 & & 0.407 & & 0.604 & \\
\hline Bodily pain & 0.460 & & 0.993 & & 0.918 & & 0.307 & \\
\hline General health & 0.927 & & 0.906 & & 0.337 & & 0.856 & \\
\hline Vitality & 0.295 & & 0.588 & & 0.339 & & 0.295 & \\
\hline Social functioning & 0.748 & & 0.893 & & 0.080 & & 0.793 & \\
\hline Role emotional & 0.473 & & 0.232 & & 0.425 & & 0.590 & \\
\hline Mental health & 0.790 & & 0.339 & & 0.512 & & 0.578 & \\
\hline Physical component summary & 0.355 & & 0.340 & & 0.363 & & 0.771 & \\
\hline Mental component summary & 0.711 & & 0.487 & & 0.278 & & 0.897 & \\
\hline & & Circulat & complai & & $\mathbf{R e}$ & atory & nplaints & \\
\hline SF-36 domains & & $P$ value & & & $\mathbf{P v}$ & & ES & \\
\hline Physical functioning & & 0.007 & & 44 & 0.1 & & & \\
\hline Role physical & & 0.066 & & & 0.3 & & & \\
\hline Bodily pain & & 0.613 & & & 0.4 & & & \\
\hline General health & & 0.129 & & & 0.2 & & & \\
\hline Vitality & & 0.704 & & & 0.8 & & & \\
\hline Social functioning & & 0.933 & & & 0.9 & & & \\
\hline Role emotional & & 0.832 & & & 0.2 & & & \\
\hline Mental health & & 0.500 & & & 0.6 & & & \\
\hline Physical component summary & & 0.041 & & 39 & 0.5 & & & \\
\hline Mental component summary & & 0.766 & & & 0.8 & & & \\
\hline
\end{tabular}

*Higher SF-36 scores (all other effect sizes (ESs) were lower). Cohen's d was used to calculate the ES of between-group differences.

$P$ value in bold denotes less than 0.05 .

FAs rated their HRQoL worse than both the Swedish norm population and controls in all SF-36 domains. ES for the differences between FAs and norms was large for seven of eight domains, reflecting an increased frequency of both physical and mental health problems.
These results, aligning with previous findings obtained using different HRQoL metrics, underscore that there is a conceptual replicability irrespective of the instruments used, which, in turn, suggests a robust effect. $^{27} 353745$ 
Table 4 Subgroup analyses of frequent attenders in Swedish primary care with regard to obesity and sex with short-form health survey (SF-36) domains as outcome measures.

\begin{tabular}{|c|c|c|c|}
\hline \multirow[b]{2}{*}{ SF-36 domains } & \multicolumn{2}{|l|}{$\mathrm{BMI} \geq \mathbf{3 0}$} & Sex \\
\hline & $P$ value & ES & $P$ value ES \\
\hline Physical functioning & 0.000 & 0.72 & 0.252 \\
\hline Role physical & 0.912 & & 0.509 \\
\hline Bodily pain & 0.231 & & 0.404 \\
\hline General health & 0.040 & 0.32 & 0.144 \\
\hline Vitality & 0.262 & & 0.251 \\
\hline Social functioning & 0.290 & & 0.458 \\
\hline Role emotional & 0.883 & & 0.498 \\
\hline Mental health & 0.735 & & 0.795 \\
\hline $\begin{array}{l}\text { Physical component } \\
\text { summary }\end{array}$ & 0.073 & & 0.666 \\
\hline $\begin{array}{l}\text { Mental component } \\
\text { summary }\end{array}$ & 0.849 & & 0.408 \\
\hline
\end{tabular}

Cohen's d was used to calculate the effect size (ES) of betweengroup differences.

In addition, FAs with predominantly musculoskeletal pain or psychosocial distress attribute their health problems to domains consistent with their reasons for GP visits. Despite the fact that FAs visited GPs with several complaints during the study period, an analysis of each complaint group consistently showed poor HRQoL, even when analyses were performed by taking each complaint into account.

FAs who reported musculoskeletal pain as major causes for visits had low SF-36 scores on domains measuring physical distress, while FAs who presented psychosocial distress displayed low scores on social and psychological domains. For patients complaining of infections, data indicate that most health areas are affected. It should be noted that most people suffer infections from time to time regardless of their overall health status. As the current study is based on the reasons FAs and CGs had to visit their GP, there were available to us no diagnoses made by GPs. No FA or CG reported infection as sole reason for the encounter during the study period.

It has been pointed out that FAs themselves feel they are not taken seriously by the healthcare system and that their symptoms are neither ignored nor addressed. ${ }^{46}$ FAs tend to view themselves as a burden on others and try to conceal their inadequacy, ${ }^{47}$ which has been confirmed in studies aimed at reducing GP visits. ${ }^{43}$ In addition, there has been great interest in psychological and psychiatric explanations for the excessive help-seeking on the part of FAs, ${ }^{48}$ and psychological or psychiatric reasons for these visits are not disputed by the FAs themselves. ${ }^{1} \mathrm{~A}$ multidisciplinary approach including psychiatry and primary care may be advantageous. ${ }^{49}$ There is some consensus regarding the characteristics of FAs, but it should be noted that this is a heterogeneous group both with respect to mental and physical symptomatology. However, cognitive strategies, attributions, and behaviours linked to frequent attendance are important subjects for future research. Psychological assessment might be useful in combination with proper medical care for the health issues presented.

\section{CONCLUSIONS}

The quality of life is compromised in frequent attenders, both when compared with patients who do not seek healthcare often and to age-matched and sex-matched general Swedish population norms. This is true for all domains covered by SF-36 and reflected in the FAs' perceived reduced mental and physical health. Commonly reported reasons for visiting GPs among FAs were musculoskeletal pain and psychosocial distress. Thus, perceived ill health, particularly pain and distress, seem important for high utilisation of healthcare.

Acknowledgements The authors acknowledge editing by Jo Ann LeQuang of LeQ Medical who reviewed the manuscript for American English use, Ivar Lund Olsen for consultations of medical records and Lennart Melin for sharing knowledge and experience.

Contributors YS: design, statistics, data analysis and interpretation, writing the article, project management. PM: statistics, data analysis and interpretation, writing the article, project management. JK: statistics, data analysis and interpretation, critical revision. MF: data analysis and interpretation, critical revision.

Funding The Region Gävleborg and FINSAM funded this research project. Competing interests None declared.

Patient consent for publication Not required.

Ethics approval The study was approved by the Gävle-Dala research ethics committee Dnr 2000346. All participants returned a written informed consent and the study was conducted according to the principles of the Declaration of Helsinki [50]. Data were coded in order to ensure confidentiality.

Provenance and peer review Not commissioned; externally peer reviewed.

Data sharing statement We have decided to not share any original data but can do that upon request.

Open access This is an open access article distributed in accordance with the Creative Commons Attribution Non Commercial (CC BY-NC 4.0) license, which permits others to distribute, remix, adapt, build upon this work non-commercially, and license their derivative works on different terms, provided the original work is properly cited, appropriate credit is given, any changes made indicated, and the use is non-commercial. See: http://creativecommons.org/licenses/by-nc/4.0/.

\section{REFERENCES}

1. Gill D, Sharpe M. Frequent consulters in general practice: a systematic review of studies of prevalence, associations and outcome. J Psychosom Res 1999;47:115-30.

2. Heywood PL, Blackie GC, Cameron IH, et al. An assessment of the attributes of frequent attenders to general practice. Fam Pract 1998;15:198-204.

3. Neal RD, Wickenden G, Cottrell D, et al. The use of primary, secondary, community and social care by families who frequently consult their general practitioner. Health Soc Care Community 2001;9:375-82.

4. Bergh $\mathrm{H}$, Marklund B. Characteristics of frequent attenders in different age and sex groups in primary health care. Scand J Prim Health Care 2003;21:171-7.

5. Neal RD, Heywood PL, Morley S, et al. Frequency of patients' consulting in general practice and workload generated by frequent attenders: comparisons between practices. $\mathrm{Br} J$ Gen Pract 1998;48:895-8. 
6. Browne GB, Humphrey B, Pallister R, et al. Prevalence and characteristics of frequent attenders in a prepaid Canadian family practice. J Fam Pract 1982;14:63-71.

7. Neal RD, Heywood PL, Morley S. 'I always seem to be there'-a qualitative study of frequent attenders. $\mathrm{Br} J$ Gen Pract 2000;50:716-23.

8. Katon W, Von Korff M, Lin E, et al. Distressed high utilizers of medical care. DSM-III-R diagnoses and treatment needs. Gen Hosp Psychiatry 1990;12:355-62.

9. Katon W, Lin E, Von Korff M, et al. Somatization: a spectrum of severity. Am J Psychiatry 1991;148:34-40.

10. Von Korff M, Ormel J, Katon W, et al. Disability and depression among high utilizers of health care. A longitudinal analysis. Arch Gen Psychiatry 1992;49:91-100.

11. Lin EH, Katon W, Von Korff M, et al. Frustrating patients: physician and patient perspectives among distressed high users of medical services. J Gen Intern Med 1991;6:241-6.

12. Courtenay MJF, Curwen MP, Dawe D, et al. Frequent attendance in a family practice. J R Coll Gen Pract 1974;24:251-61.

13. Westhead JN. Frequent attenders in general practice: medical, psychological and social characteristics. J R Coll Gen Pract 1985;35:337-40.

14. Svab I, Zaletel-Kragelj L. Frequent attenders in general practice: a study from Slovenia. Scand J Prim Health Care 1993;11:38-43.

15. Karlsson $H$, Lehtinen V, Joukamaa M. Frequent attenders of Finnish public primary health care: sociodemographic characteristics and physical morbidity. Fam Pract 1994;11:424-30.

16. Karlsson $\mathrm{H}$, Lehtinen $\mathrm{V}$, Joukamaa $\mathrm{M}$. Are frequent attenders of primary health care distressed? Scand $J$ Prim Health Care 1995;13:32-8.

17. Karlsson $\mathrm{H}$, Lehtinen $\mathrm{V}$, Joukamaa $\mathrm{M}$. Psychiatric morbidity among frequent attender patients in primary care. Gen Hosp Psychiatry 1995;17:19-25.

18. Joukamaa M, Karlsson H, Sholman B, et al. Alexithymia and psychological distress among frequent attendance patients in health care. Psychother Psychosom 1996;65:199-202.

19. Weimer SR, Hatcher C, Gould E. Family characteristics in high and low health care utilization. Gen Hosp Psychiatry 1983;5:55-61.

20. Karlsson H, Joukamaa M, Lahti I, et al. Frequent attender profiles: different clinical subgroups among frequent attender patients in primary care. J Psychosom Res 1997;42:157-66.

21. Wamoscher $Z$. The returning patient: a survey of patients with high attendance rate. J Coll Gen Pract 1966;11:166-73.

22. Schrire S. Frequent attenders--a review. Fam Pract 1986;3:272-5.

23. McArdle C, Alexander WD, Boyle CM. Frequent attenders at a health centre. Practitioner 1974;213:696-702.

24. Semmence A. Chronic high users in a general practice. J Roy Coll Gen Pract 1969;17:304-10.

25. Robinson JO, Granfield AJ. The frequent consulter in primary medical care. J Psychosom Res 1986;30:589-600.

26. Morris JK, Cook DG, Walker M, et al. Non-consulters and high consulters in general practice: cardio-respiratory health and risk factors. J Public Health Med 1992;14:131-7.

27. Patel S, Kai J, Atha C, et al. Clinical characteristics of persistent frequent attenders in primary care: case-control study. Fam Pract 2015;32:cmv076-30.

28. Pymont C, Butterworth P. Longitudinal cohort study describing persistent frequent attenders in Australian primary healthcare. BMJ Open 2015;5:e008975.

29. Statistics Sweden. Statistikdatabasen SCB. http://www. statistikdatabasen.scb.se/pxweb/sv/ssd/START_BE_BE0101_ BE0101A

30. Folkhälsorapport, Socialstyrelsen. 1997.
31. Jyväsjärvi S, Keinänen-Kiukaanniemi S, Väisänen E, et al. Frequent attenders in a Finnish health centre: morbidity and reasons for encounter. Scand J Prim Health Care 1998;16:141-8.

32. McHorney CA, Ware JE, Lu JF, et al. The MOS 36-item ShortForm Health Survey (SF-36): III. Tests of data quality, scaling assumptions, and reliability across diverse patient groups. Med Care 1994;32:40-66.

33. Sullivan M, Karlsson J, Ware JE. The Swedish SF-36 Health Survey$-I$. Evaluation of data quality, scaling assumptions, reliability and construct validity across general populations in Sweden. Soc Sci Med 1995;41:1349-58.

34. Cohen L. Statistical power analysis for the behavioral sciences. Hillsdale, NJ: Erlbaum, 1988.

35. Bergh $\mathrm{H}$, Baigi A, Fridlund B, et al. Life events, social support and sense of coherence among frequent attenders in primary health care. Public Health 2006;120:229-36.

36. Scaife B, Gill P, Heywood P, et al. Socio-economic characteristics of adult frequent attenders in general practice: secondary analysis of data. Fam Pract 2000;17:298-304.

37. Kersnik J, Svab I, Vegnuti M. Frequent attenders in general practice: quality of life, patient satisfaction, use of medical services and GP characteristics. Scand J Prim Health Care 2001;19:174-7.

38. Smits FT, Mohrs JJ, Beem EE, et al. Defining frequent attendance in general practice. BMC Fam Pract 2008;9:21.

39. Frass M, Strassl RP, Friehs $\mathrm{H}$, et al. Use and acceptance of complementary and alternative medicine among the general population and medical personnel: a systematic review. Ochsner $J$ 2012;12:45-56.

40. Kersnik J. Predictive characteristics of users of alternative medicine. Schweiz Med Wochenschr 2000;130:390-4.

41. Sundquist J, Johansson SE, Sundquist K. Levelling off of prevalence of obesity in the adult population of Sweden between 2000/01 and 2004/05. BMC Public Health 2010;10:119.

42. Savageau JA, McLoughlin M, Ursan A, et al. Characteristics of frequent attenders at a community health center. J Am Board Fam Med 2006;19:265-75.

43. Bellón JA, Rodríguez-Bayón A, de Dios Luna J, et al. Successful GP intervention with frequent attenders in primary care: randomised controlled trial. Br J Gen Pract 2008;58:324-30.

44. Smits FT, Brouwer HJ, Zwinderman AH, et al. Morbidity and doctor characteristics only partly explain the substantial healthcare expenditures of frequent attenders: a record linkage study between patient data and reimbursements data. BMC Fam Pract 2013;14:138.

45. Pymont $C$, Butterworth P. Changing circumstances drive changing attendance: a longitudinal cohort study of time varying predictors of frequent attendance in primary health care. $J$ Psychosom Res 2015;79:498-505.

46. Wiklund-Gustin L. To intend to but not being able to: frequent attenders' experiences of suffering and of their encounter with the health care system. $J$ Holist Nurs 2011;29:211-20.

47. Wiklund-Gustin L. Struggling on my own: a cognitive perspective on frequent attenders' conception of life and their interaction with the healthcare system. Psychiatry J 2013;2013:1-9.

48. Smits FT, Brouwer HJ, Zwinderman AH, et al. Why do they keep coming back? Psychosocial etiology of persistence of frequent attendance in primary care: a prospective cohort study. $J$ Psychosom Res 2014;77:492-503.

49. Bestall J, Siddiqi N, Heywood-Everett S, et al. New models of care: a liaison psychiatry service for medically unexplained symptoms and frequent attenders in primary care. BJPsych Bull 2017;41:340-4.

50. WMADo $\mathrm{H}$. Ethical principles for medical research involving human subjects. JAMA 2013;310. http://jama.jamanetwork.com/ by a American Medical Association User on 09/23/2015 Adopted by the 18th WMA General Assembly, Helsinki, Finland, June 1964, amended by the 64th WMA General Assembly, Fortaleza, Brazil, October 2013. 